\title{
Intelligent Technologies in Modelling and Control of Turbojet Engines
}

\author{
Ladislav Madarász, Rudolf Andoga and Ladislav Fôző \\ Technical University of Košice \\ Slovakia
}

\section{Introduction}

The state of present technologies in technical and also non-technical practice is represented by growing complexity of systems. A turbojet engine as a complex system is multidimensional highly parametric system with complex dynamics and strong non-linear behavior with stochastic properties. Its particular property is operation in a wide spectrum of changes of its operating environment (e.g., temperatures from -60 to $+40{ }^{\circ} \mathrm{C}$, different humidity, different pressures, etc.). If we want to secure optimal function of such system, it is necessary to develop models and control systems implementing the newest knowledge from the areas of automation, control technologies preferably with elements of artificial intelligence (AI). The present control systems and dynamic models are often limited to control or modeling of a complex system in its certain (operational) states. However, in practice the turbojet engine finds itself in very different operating conditions that influence its parameters of operation and characteristics. To create progressive control algorithms for a turbojet engine, it is necessary to design models in the whole dynamic spectrum of the modeled system including its erroneous states. Furthermore we need to design a control system that will secure operation converging towards optimality in all eventual states of working environment and also inner states of the system represented by its parameters. This leads to the need of having increased intelligence of control of turbojet engines that reduces workload of a pilot and also increases safety of operation. Safety represents a decisive factor in design of control systems of turbojet engines and is presently bound with increasing authority of them. The present trend designates such control systems as FADEC - Full Authority Digital Engine Control, however in reality such control systems have different levels of authority, intelligence and come in very different implementations. These are often not presented as they are intellectual properties of commercial companies. The article will be aimed on description of some present trends in development of FADEC systems and own proposals of methodologies leading towards design and implementation of a FADEC system with high level of intelligence able to solve all operational situations of a turbojet engine. This is strictly bound with presentation of modern methods of modeling of turbojet engines and the use of advanced methods of mainly sub-symbolic artificial intelligence. The proposed methods are all tested in real-world environment using a small turbojet engine MPM-20 in our laboratory setup. Therefore the article will also deal with approaches in digital real-time measurement of state parameters of this engine and design of control algorithms from engineering standpoint. 


\section{Modern control systems of turbojet engines}

The main global aim of control of turbojet engines is similar to other systems and that lies in increasing their safety and effectiveness by possible reduction of costs. This requires application of new technologies, materials and new conceptual solutions. One mean to achieve that is the development in systems of control and regulation of the engines themselves and processes ongoing in them.

Demands for control and regulation systems result mainly from specific properties of the object of control - a turbojet engine. The basic functions of control systems of a turbojet engine are the following ones - manual control, regulation of its parameters and their limitation. Manual control and therefore choice of regime of the engine is realized by a throttle lever according to a flight situation or expected maneuver. By regulation of a turbojet engine we understand such a kind of control where the chosen parameters of the engine are maintained on certain set levels, thus keeping its regime.

In the past, the classical control systems of turbojet engines were implemented mainly by hydro-mechanical elements, which however suffered from deficiencies characteristic for such systems. Among such deficiencies were, high mass of such systems, inaccuracies due to mechanical looses and low count of regulated parameters. However development of electronic systems and their elements is ongoing, which will allow to increase precision of regulation of parameters of turbojet engines and their count to secure more complex and precise control of turbojets.

Use of electronics and digital technologies in control systems of turbojet engines has brought: (Lazar, 2000):

- lowering of mass of control system

- $\quad$ higher complexity of control - The count of regulated parameters used to be 3 to 7 by hydro-mechanical systems, however the digital systems operate with 12 to 16 parameters;

- increasing of static precision of regulation of different parameters (for example, precision of rotations from $\pm 0.5 \%$ to $\pm 0.1 \%$, precision of regulation of temperature from $\pm 12 \mathrm{~K}$ to $\pm 5 \mathrm{~K}$

- increase in reliability, service life and economics of operation of the driving unit of an aircraft;

- $\quad$ easier backup, technology of use and repairs, possibility of use of automatic diagnostics. By design of solution of a control system for a turbojet engine, it is necessary to build an appropriate mathematical model of the engine. The ideal approach to design of electronic systems is a modular one, from hardware or software point of view. This implies use of qualitative processing units that are resistant to noises of environment and also realization of bus systems with low delays is very important in this approach. Further improvement in quality of control can be achieved by implementation of progressive algorithms of control, diagnostics and planning in electronic systems. These algorithms have to be able to asses the state of the controlled system (turbojet engine in our case), then parameterize action elements and they have to be able to control the engine under erroneous conditions represented in outer environment or as errors in subsystems of the engine itself. Prediction of such states represents an area to incorporate predictive control system. Methods of situational control bound with elements of artificial intelligence supply many robust tools for solution of afore mentioned problems and sub-problems. 
From the point of view of use of electrical and electronic systems in controls the turbojet control systems can be roughly hierarchically divided into following sets (Lazar, 2000):

1. Electronic limiters,

2. Partial Authority Flight Control Augmentation (PAFCA,

3. „High Integration Digital Electronic Control“ (HIDEC); „Digital Engine Control“ (DEC); „Full Authority Digital Engine Control“ - (FADEC)).

The division of control systems into these three levels is not absolutely distinct, as systems on higher level as for example HIDEC system can utilize control mechanisms as electronic limiters. For example FADEC systems are often realized as single or double loop control systems with utilization of PI control algorithms or electronic limiters with estimation filters (Jonathan, 2005; Sanjay, 2005). Example of such FADEC algorithm is shown in figure 1 (Jonathan, 2005).

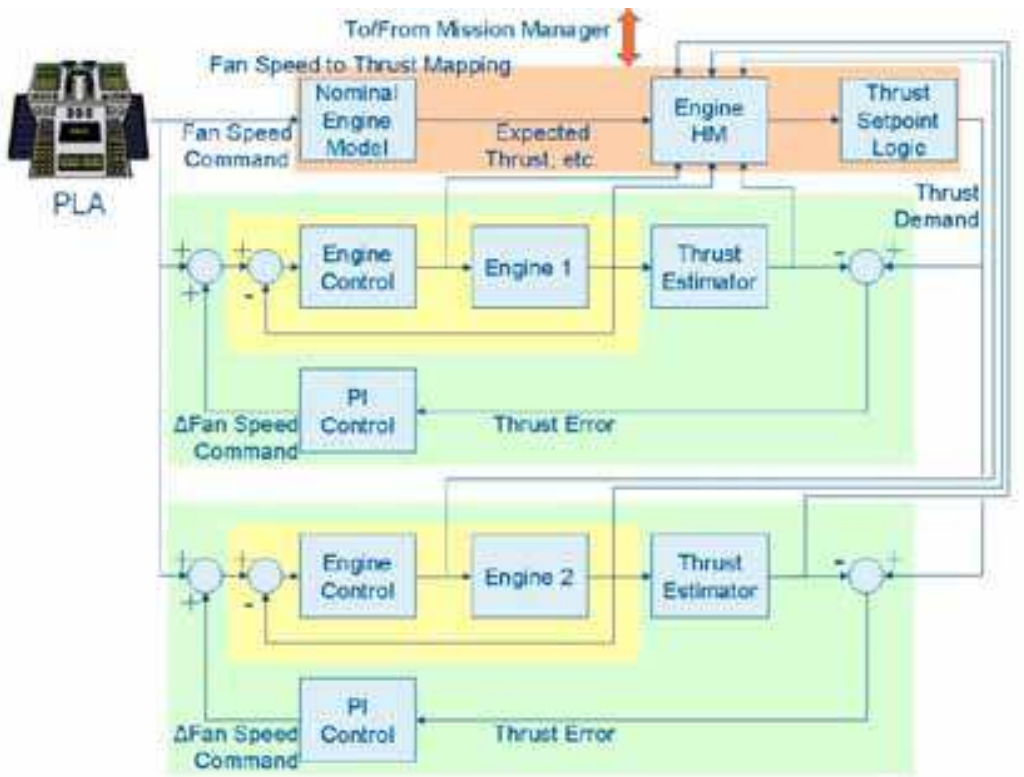

Fig. 1. FADEC control system with implemented PI electronic controllers

Such engine control systems are often integrated into the whole framework of an aircraft control system.

\section{Full authority control systems}

There are of course many possibilities and methodologies applicable to control systems of turbojet engines, which are FADEC compliant. Such application has to cope with strong non-linearity and changing structure of models and constants during operation of a turbojet engine. Such intelligent system should also be able to form decisions and predict faults either in control circuit or the object of turbojet engine itself. Therefore intelligent turbojet engine control is often bound with design of intelligent diagnostics systems (Wiseman, 2005) that also deal with control of an engine during its long-term deterioration. Example of such control based on diagnostics modules is shown in figure 2 . 


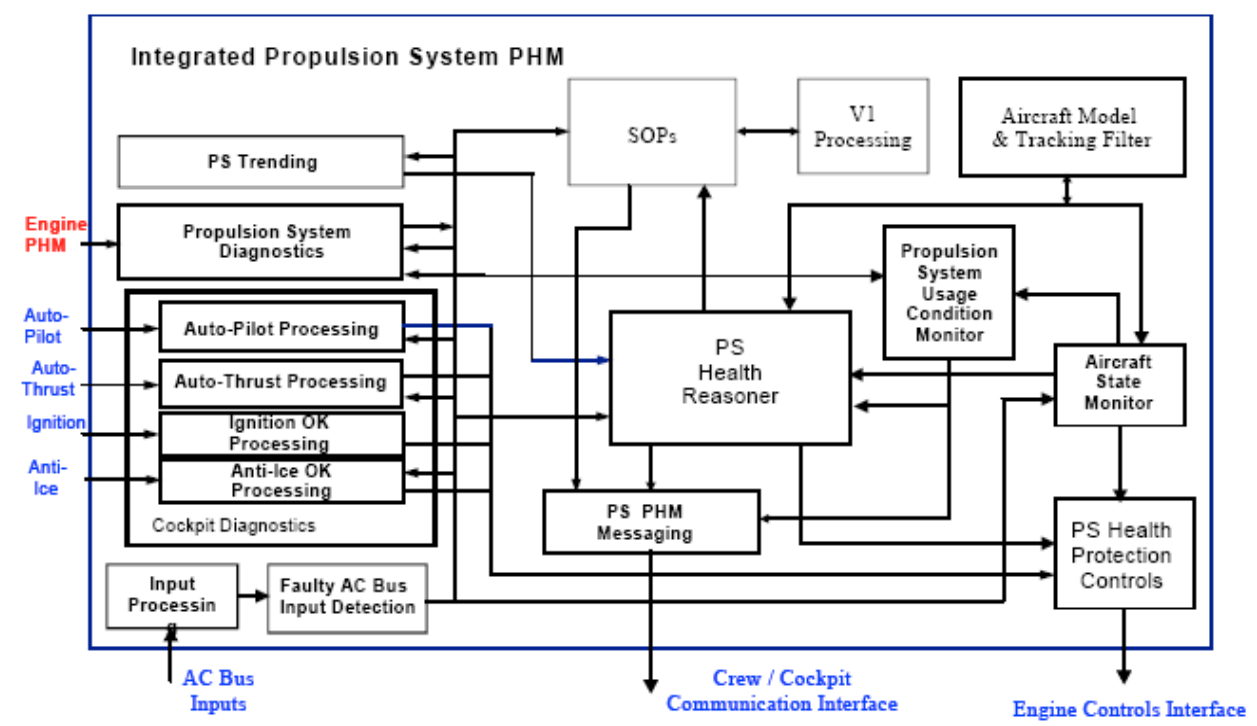

Fig. 2. Diagnostic FADEC control system of a turbojet engine (Wiseman, 2005)

The control system in this case is based on intelligent PHM (Prognostics Health Management) of the engine. Diagnostic systems of turbojet engines can be further realized by means of artificial intelligence. In design of diagnostic and control system which would control the engine in its erroneous states and act long before actual critical states develops itself; we need to form exact dynamic models of the engine. In design of classic control systems only first to second order linear models are commonly used. Methods of AI however offer possibilities of modeling the dynamic parameters of an engine in multi variable space with great precision in the whole range of operation of engine. Such models can have precision within $2 \%$ of standard error in whole area of operation of a jet engine (Andoga, 2006). Integrated model used for control of a turbojet engine can be seen in figure 1. Importance of modeling during operation of a turbojet engine can be further extended to fault detection of sensors and other parts of control system and the engine itself. In design of control system, the architecture also plays a significant role. Two common architectures can be presently found in design of turbojet engine FADEC control systems (Sanjay, 2007). The first one is the centralized one, which is reliable and well understood, but on the other hand has many drawbacks like inflexibility, high weight, complicated fault detection, etc. This architecture is shown in the figure 3.

The other usable architecture for design is the distributed architecture (fig. 4). Its main advantage is high flexibility, easier fault detection and isolation, its cons are mainly higher complexity, communication unknowns and deterministic behavior and it requires new technologies, i.e. high temperature electronics for use in turbojet engines.

The basic element of the FADEC control system is the electronic engine control (EEC) unit that represents the main computer (outlined in black, in the previous figures). Such systems that are presently used to control common commercial airliners' engines can be schematically depicted in the following figure 4 (Linke-Diesenger, 2008). 

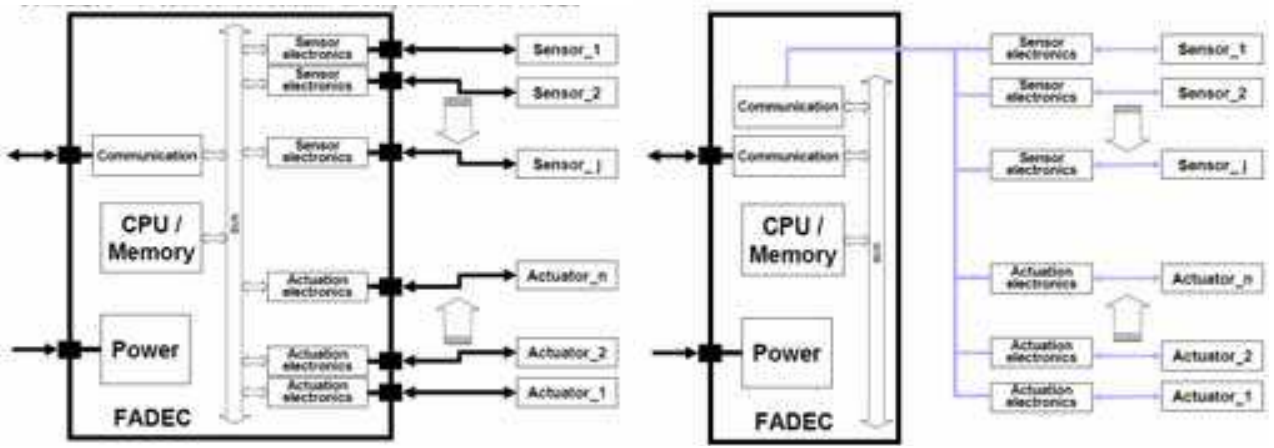

Fig. 3. Centralized (left) and decentralized (right) FADEC architectures (Sanjay, 2007)

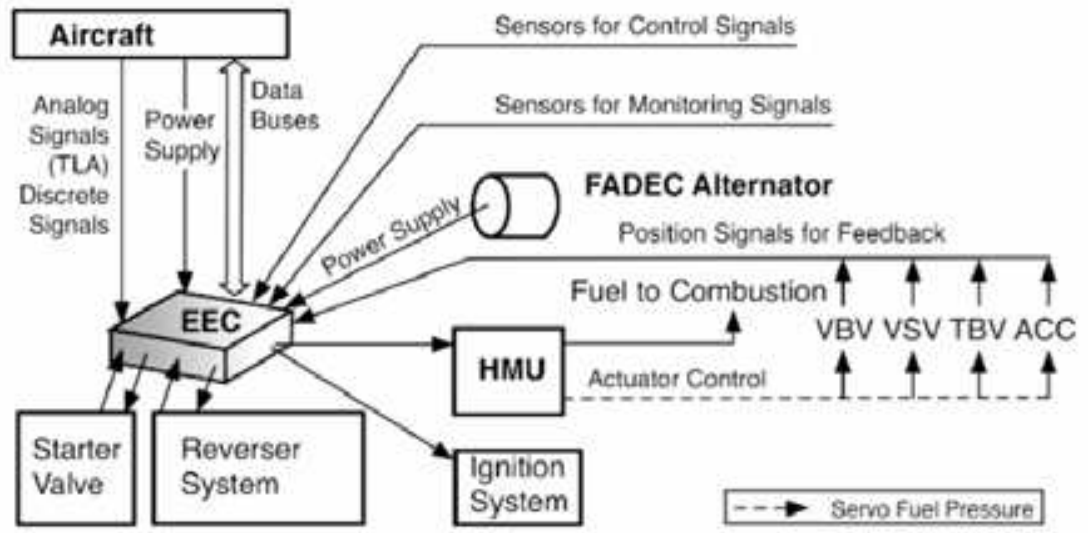

Fig. 4. The system architecture of a FADEC system with the centralized arrangement of servo valves in an HMU (Linke-Diesenger, 2008)

\section{Small turbojet engine - MPM 20}

The experimental engine MPM 20 has been derived from the TS - 20 engine, which is a turbo-starter turbo-shaft engine previously used for starting engines AL-7F and AL-21F. The engine has been rebuilt to a state, where it represents a single stream engine with radial compressor and a single stage non-cooled turbine and outlet jet. The basic scheme of the engine is shown in the figure 5

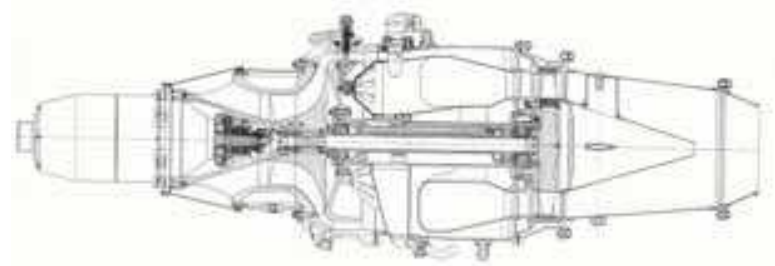

Fig. 5. The basic scheme of MPM 20 engine 
All sensors, except fuel flow and rotations sensor, are in fact analogue and have voltage output. This is then digitalized by a SCXI measurement system and corresponding A/D converters and sent through a bus into computer. Every parameter is measured at the sampling rate of $10 \mathrm{~Hz}$. The data acquisition has been done in LabView environment. The digital measurement of parameters of MPM-20 engine in real time is important to create a model and control systems complying with FADEC definition („Full Authority Digital Electronic Engine Control“). Moreover we needed to change the engine from static single regime engine into a dynamic object, what was done by regulation of pressure beyond the compressor according to which the current fuel supply actuator changes actual fuel supply for the engine in real time. The system has been described in (Andoga, 2006). The graph in figure 6 shows dynamic changes of parameters of the engine to changes of fuel supply input.

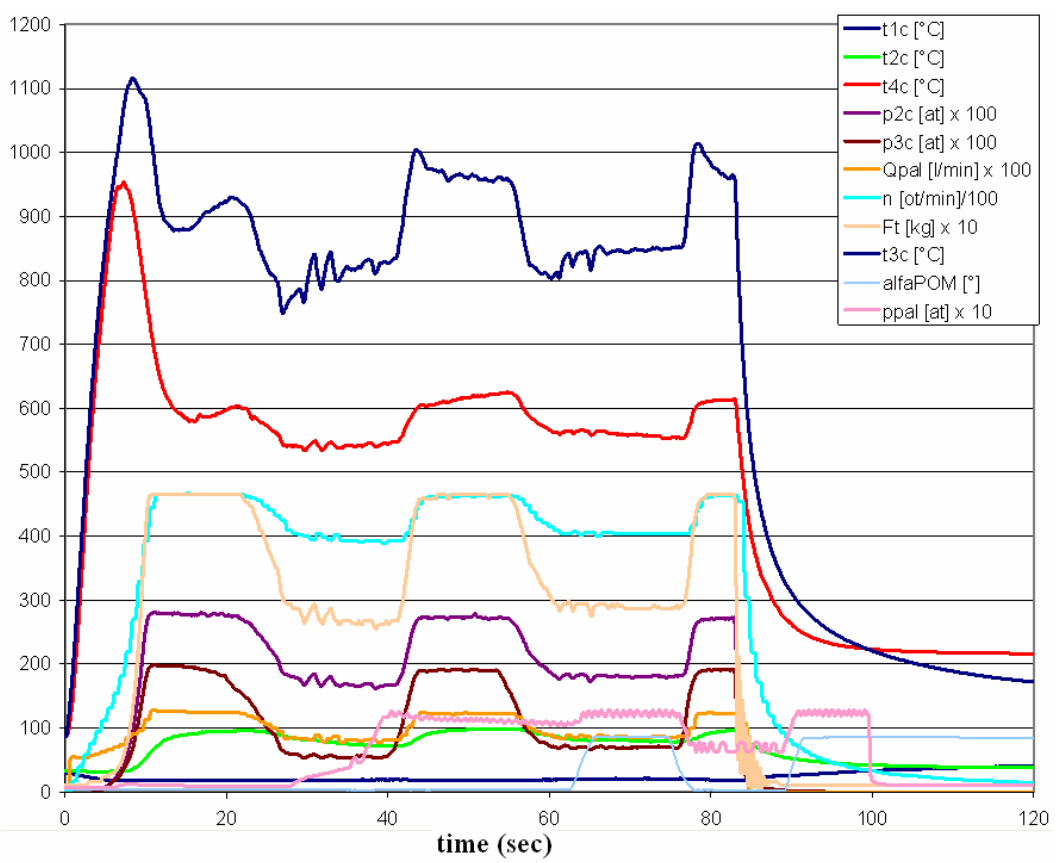

Fig. 6. One run of the engine with changes in fuel flow supply

The following basic parameters are measured:

- $\quad$ air temperature at the outlet from the diffuser of the radial compressor $-\mathrm{T}_{2 \mathrm{C}}\left[{ }^{\circ} \mathrm{C}\right]$;

- gas temperatures in front of the gas turbine $-\mathbf{T}_{\mathbf{3}} \mathbf{C}\left[{ }^{\circ} \mathrm{C}\right]$;

- $\quad$ gas temperature beyond the gas turbine $-\mathrm{T}_{4 \mathbf{C}}\left[{ }^{\circ} \mathrm{C}\right]$;

- $\quad$ static pressure of air beyond the compressor $\mathrm{P}_{\mathbf{2}}$ [Ata];

- $\quad$ static pressure of gases in front of the gas turbine $P_{3}[$ Ata];

- $\quad$ static pressure of gases beyond the gas turbine $\mathrm{P}_{4}[\mathrm{Ata}] ;$

- fuel flow supply $Q_{\text {pal }}[1 / \mathrm{min}] ;$

- $\quad$ thrust Th [kg];

- $\quad$ rotations of the turbine/compressor, $\mathrm{n}_{1}$ [rpm]. 


\section{Modeling of turbojet engines}

\subsection{Basic approaches in modeling of turbojet engines}

In order to design and develop a control system for a turbojet engine, its mathematical model has to be constructed. In mathematical modeling of technical systems, many approaches can be used for different purposes. Specifically in the area of turbojet engines modeling two basic can be used. The first one is the analytic one that is usually developed under equilibrium conditions and uses physical relations and formulas to model usually static characteristics of different areas of an engine like inlet system, compressor, combustion chamber, etc. Such model is mainly used in design of the engine itself and to estimate basic operating parameters and envelopes in different environments. Basic control laws can be also estimated from such model. The second approach used mainly in design of control algorithms and diagnostic systems lies in creation of dynamic experimental models that model the engine or its parts as black boxes as transfer functions between input and output parameters (Harris, et. al, 2006). These models are aimed on simulation of dynamic behavior and regimes of an engine. To create a complex and intelligent control system both approaches have to be used and the further sections of this chapter will show some of these approaches to create precise computational models with use of elements of artificial intelligence. The authors of the paper deal with both approaches in modeling and as a realworld object a small turbojet engine MPM-20 is used.

\subsection{Analytic modeling}

Static and dynamic properties of turbojet engines (MPM-20) can also be described by a mathematical model of operation single stream engine under equilibrium or nonequilibrium conditions. This will allow modeling the thrust, fuel consumption, pressures and temperatures of the engine by different altitudes and velocities in the chosen cuts of the engine.

The steady operation of the engine is such a regime, where in every element of the engine same thermodynamic processes are realized. Operation of an engine in its steady operation can be described by:

1. algebraic equations of balance of mass flow of working materials through nodes of the engine, equations of output balance, equations of regulation rules and equations describing particular oddities of an engine. A system of equations expresses that for given outer conditions of operation of an engine, characteristics of all nodes of an engines and preset values of control parameters (fuel supply, cross section of the output nozzle, angle of compressor blades), operation of the engine will settle itself on one and only one regime (Ružek, Kmoch, 1979) .

2. graphically by utilization of knowledge of characteristics of all parts (output, compressor, turbine, etc) of the engine and their preset curves of joint operations (e.g. lines of stable rations of $\mathrm{T}_{3 c} / \mathrm{T}_{1 \mathrm{c}}$ in compressor). Designation of all curves of the engine is done in a way that we will try to fulfill continuity conditions for all parts of the engine and characteristics of all these parts are given. These characteristics can be found by direct measurement, computation, etc.

Any regime of the turbojet engine has to fulfill the continuity equation which designates dependencies between mass flow of air through the compressor, turbine, combustion chamber and exhaust system (Považan, 1999): 


$$
Q_{V S}=Q_{k}=Q_{S K}=Q_{T}=Q_{t r}=Q
$$

and a condition of no distortion of the shaft

$$
n_{k}=n_{T}=n
$$

where

Qvs - mass flow of air through input system,

$\mathrm{Q}_{\mathrm{k}} \quad$ - mass flow of air through the compressor

QSK - mass flow of air through combustion chamber,

$\mathrm{Q}_{\mathrm{T}}$ - mass flow of gases through the turbine,

$Q_{\mathrm{tr}} \quad-$ mass flow of gases through exhaust nozzle,

$n_{k} \quad-$ revolutions of compressor,

$\mathrm{n}_{\mathrm{T}} \quad-$ revolutions of turbine.

Another condition for steady operation of the engine has to be fulfilled - the engine doesn't change its revolutions in time.

$$
\frac{d n}{d t}=0
$$

This condition will be fulfilled when output of the turbine will be the same as output taken by the compressor and accessories of the engine

$$
W_{K C}=\eta_{m} W_{T C}
$$

where

$\eta_{m} \quad$ - mechanical effectiveness of the engine,

$\mathrm{W}_{\mathrm{KC}}$ - technical work of the compressor,

$\mathrm{W}_{\mathrm{TC}}$ - technical work of the turbine.

A detailed algorithm of designation of operational points of steady operation of a single stream engine is described in (Főző, 2008).

Non steady operation of an engine is a regime of its operation, where in every element of the engine time changing thermodynamic processes occur. Function of the engine in such non steady regimes can be described by a system of differential and algebraic equations. Such system of equations describes transient processes by change of regime of the engine, when thrust lever is moved or other change of flight regime occurs.

Such non-steady regime occurs when work of the turbine and compressor isn't equal, this means that rotation moments of the turbine $\mathrm{M}_{\mathrm{T}}$ and compressor $\mathrm{M}_{\mathrm{K}}$ aren't equal. Acceleration of the engine is dependant upon this difference equation:

$$
M_{T}-M_{K}-M_{a g}=J \frac{d \omega}{d t}
$$

where

$\frac{d \omega}{d t} \quad$ - angular acceleration of the engine,

$\mathrm{J} \quad$ - moment of inertia of all rotating masses reduced to the shaft of the engine

$\mathrm{M}_{\mathrm{ag}} \quad$ - moment needed for actuation of aggregates and overcoming of friction. 
As the angular velocity of the MPM-20 engine is given by the equation $\omega=\frac{\pi n}{30}$ and output is given by equation $P=M \omega$, after incursion of mechanical effectiveness, the basic equation of non-steady operation of the engine is obtained:

$$
P_{T} \eta_{m}-P_{k}=J \frac{\pi^{2}}{900} n \frac{d n}{d t}
$$

Stable operation of the engine is then computed which gives us the initial conditions. Differences of revolutions are then computed in a given time space $\Delta t$ and we repeat this algorithm until the end of the transient process.

Analytic mathematical model of the engine is based on physical rules which characterize properties and operation of different nodes of the engine, thermodynamic and aerodynamic processes obtained by temperature cycle. While we have to take in account range of operation of turbojet engines which give changes of thermodynamic properties of working material.

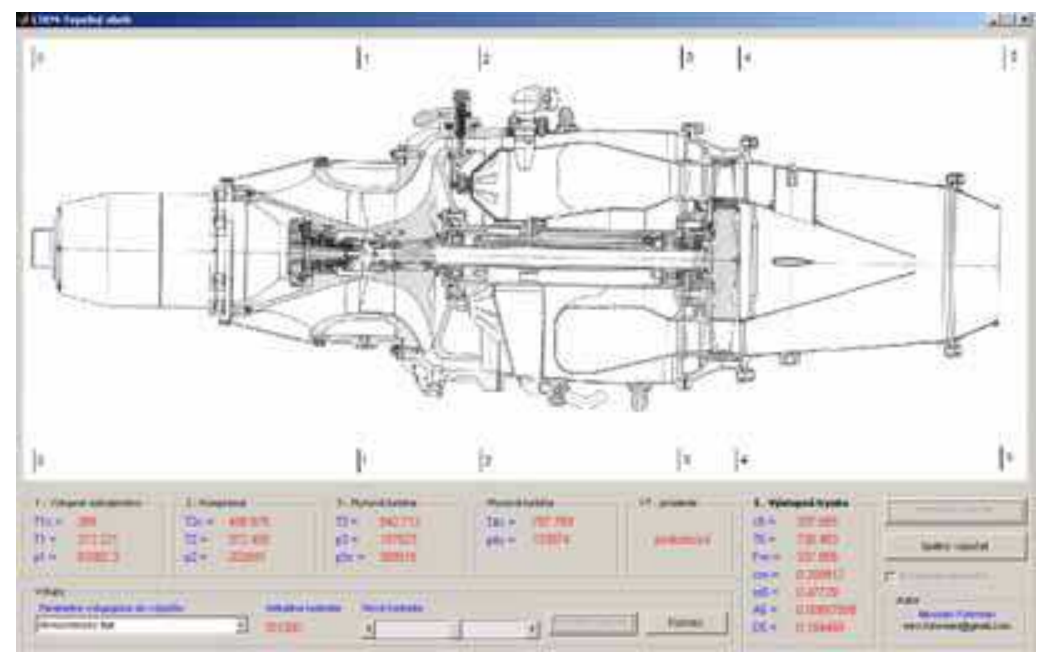

Fig. 7. Temperature circuit calculation implemented in Matlab GUI

Contrary to the experimental one, the analytical model of the engine allows us to compute parameters of the engine that cannot be simply simulated by models built upon the experimental data, which use only known parameters. This way we can compute engine surge lines, workloads on shafts, different internal temperatures and also parameters, which are measured and can be used for checking the results of the model. The analytic model allows us to compute parameters of our engine also by different values of outer pressure and temperature of air, different speed of flight and height. Complexity of the model is out of scope of this paper, the figure 8 illustrates computed curve of steady state of operation for the MPM 20 engine. X-axis denotes the air flow through the engine, Y-axis the compression ratio, red line represents surge line, green lines represent different speeds (reduced RPM's), and the dark red line represents acceleration of the engine with fast geometry of the exhaust nozzle. 


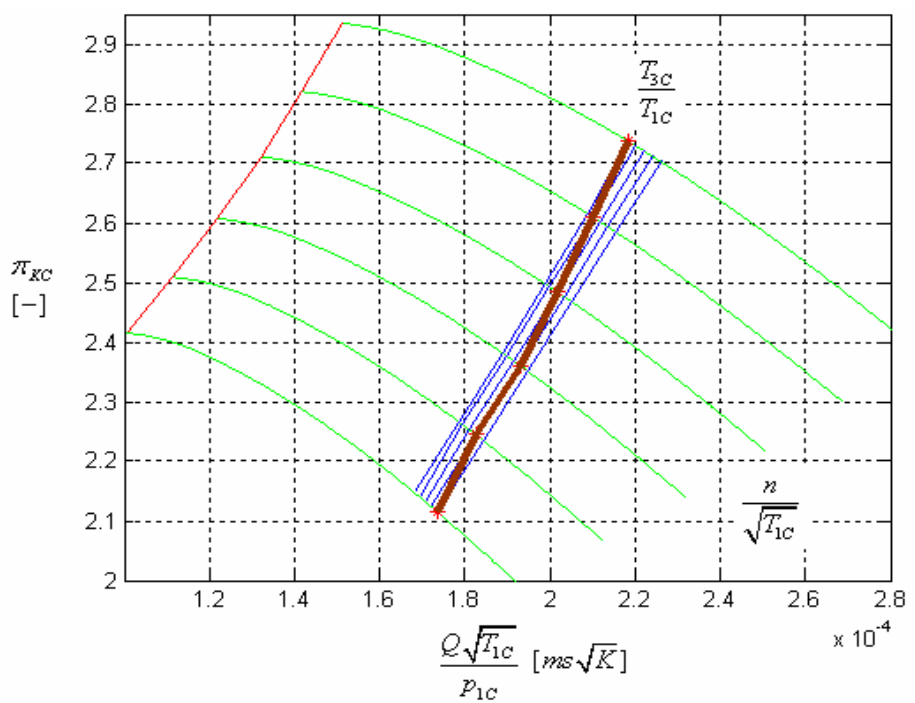

Fig. 8. The steady state line of operation of the MPM-20 engine

\subsection{Methods of artificial intelligence in analytic modeling of the MPM-20 engine}

Resulting from practical expertise of the data and created analytic models we found that adaptive fuzzy inference systems are well suited for replacing the complex equations found in analytic modelling. We used the ANFIS - Adaptive-Network-based Fuzzy Inference System (Roger Jang, 1993).

This system is based on network architecture just like the neural networks that maps input on the bases of membership fuzzy functions and their parameters to outputs. The network architecture is of feed-forward character.

To verify the ANFIS method, we are showing a simple physical dependency expressing the pressure ratio of a radial compressor, which is a type of compressor found on the MPM 20 engine.

$$
\Pi_{K C}=\left[1+\frac{u_{2}^{2}(\mu+\alpha)}{c_{p} T_{1 C}} \eta_{K C}\right]^{\frac{\kappa}{\kappa-1}}
$$

The equation can be understood as a static transfer function with two inputs - the temperature $\mathrm{T}_{1 \mathrm{c}}$ and circumferential speed $\mathrm{u}_{2}$ (speed of the compressor) and one output in the form of the pressure ratio. The surface shown in the figure 9 is equal to numeric computation of the equation 12.

The obtained results have confirmed that the chosen method ANFIS is suitable for modelling of mathematic - physical equations with very low computational demands (trained FIS system is computationally very simple) with very fine sampling periods (by very fine division of interval of values of input parameters). Therefore we will further be oriented on improvement of the complex and highly computationally demanding analytic model of the MPM 20 engine by use of AI methods, with ANFIS in particular. 


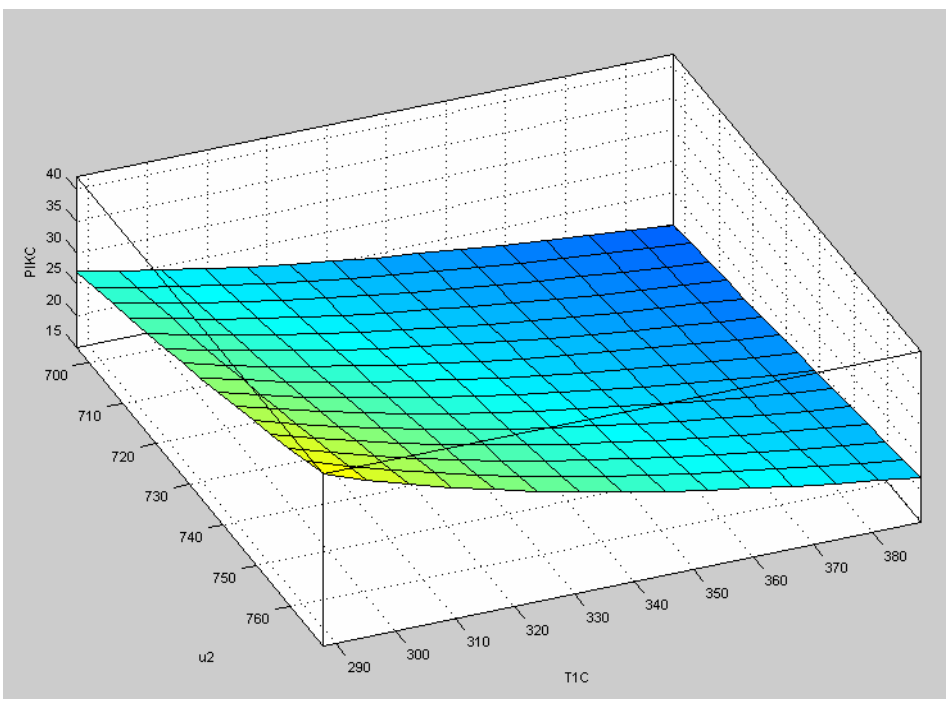

Fig. 9. The equation (7) modeled by ANFIS

\subsection{Situational modeling of the MPM-20 engine}

Individual dynamical dependencies of parameters of a turbojet engine are more complex than they can be depicted by static analytic models. In experimental modeling we will consider $T_{2 c}, T_{4 c}, P_{2 c}, n$ input parameters on $Q_{\text {pal }}$ parameter in the figure 6 . The other arising problem is that these dependencies are not stationary and are changing during course of turbojet's engine operation. In such case it isn't possible to easily set operating points in multi-dimensional non linear parametric space. The operating point will lie on a functional of the following parameters:

$$
O_{p}=f(Q p, N 1, T 4, T 2, P 2)
$$

To decompose the model into subspaces, we will use the methodology of situational modeling and decompose the model into sub-models representing certain operating points of the engine.

$$
O_{p i}=f_{i}(N 1, T 4, T 2, P 2), i=1 \ldots n
$$

where $n$ is the regimes count. This decomposition can be done by expert knowledge or with use of some clustering algorithm. We propose the decomposition of the model into a set of three operating points $(n=3)$, or in terms of situational modeling into three distinct situations (Andoga, 2006). That is the startup of the engine, stable operation of the engine and its shutdown. Every situational model is further decomposed into a set of non equivalent submodels, which are interconnected according to the basic physical dependencies in the engine and are treated as black box systems. Every one of these sub-models is then represented by a neural network or fuzzy inference system, which models the individual parameter dependencies and further decomposes the operating points into local operating points which are then represented as local neural or fuzzy models. Furthermore all models have to be put in an adaptive structure that will be able to decide, which model to use for 
certain situational frame. The modular architecture of such system is shown in the figure 10 . A classifier in the form of neural network represents the gate which gates outputs of individual models to give a correct prediction. Use of this model allows us to simulate whole operation of the engine with also highly non-linear atypical situations such as startup and shut down of the engine. The model has only a single input parameter in the form of fuel flow input $Q_{\text {pal. }}$

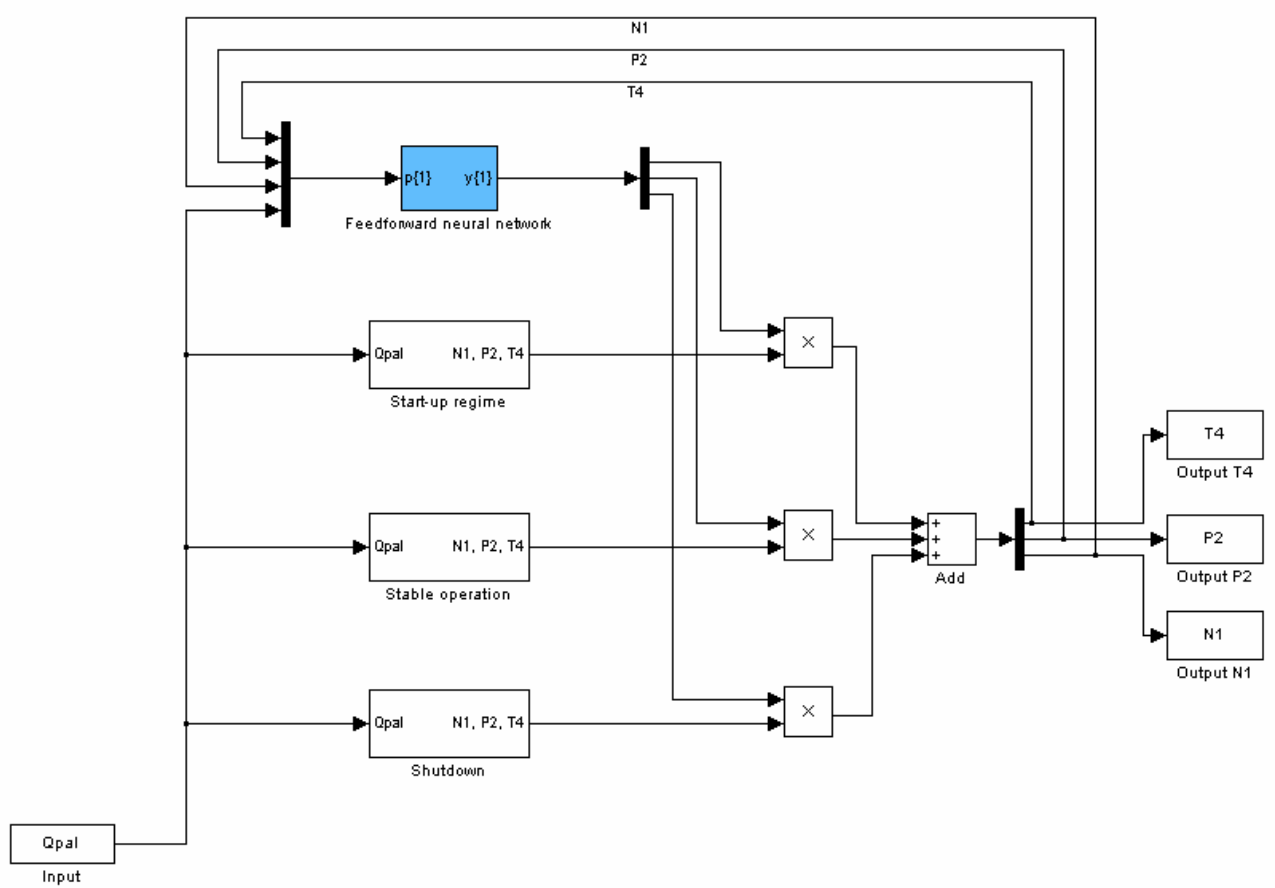

Fig. 10. Modular architecture of the dynamic engine model

The inputs for the classifier neural network are state variables resulting from the model, the only input to the model is the fuel flow parameter. The output of the network will be defined as a vector:

$$
O_{u}=\left[x_{1}, \ldots, x_{n}\right]
$$

where $n$ is the number of situational model frames and $x_{i}=\{0 ; 1\}$, in our case $n=3$.

\subsection{Simulations with the situational model of the MPM-20 engine}

We can evaluate the situational model in terms of simulating the start-up of the engine, its stable regime of operation and its run down, together with the whole operation. The figure 12 shows the plot of speed (rpm) of the engine during its startup with three different startup levels of fuel flow input. The individual sub-models for this frame are in the form of neural networks trained by scaled conjugate gradient algorithm (Moller, 1993) with the modification of time delayed inputs. The individual models are shown in the following figure. 


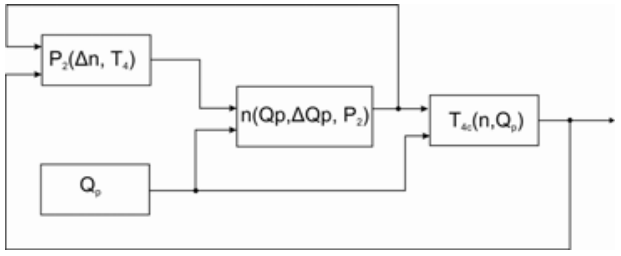

a) Startup model

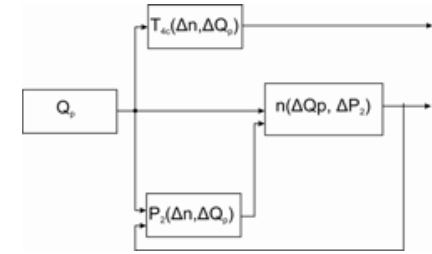

b) Steady operational state

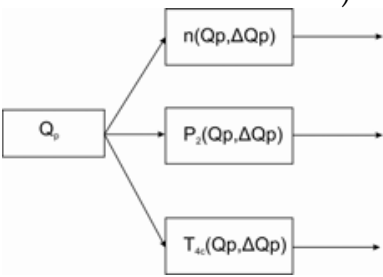

c) Shut-down state

Fig. 11.Structure of the models for three situational frames of operation of the engine.

All models were tested separately with fuel supply inputs measured by different runs of the engine and tests were also done with the whole model with 15 different consecutive runs defined by measured fuel flow supply. The model does not take in account environmental conditions as they are kept constant in the laboratory. The startup model uses time delayed feedforward neural networks with two hidden layers trained by SCG algorithm, the steady operational state model uses Takagi Sugeno (TSK) fuzzy inference systems to model individual parameter dependencies and the shut-down model uses neural networks of identical structure as the startup model trained with other data.

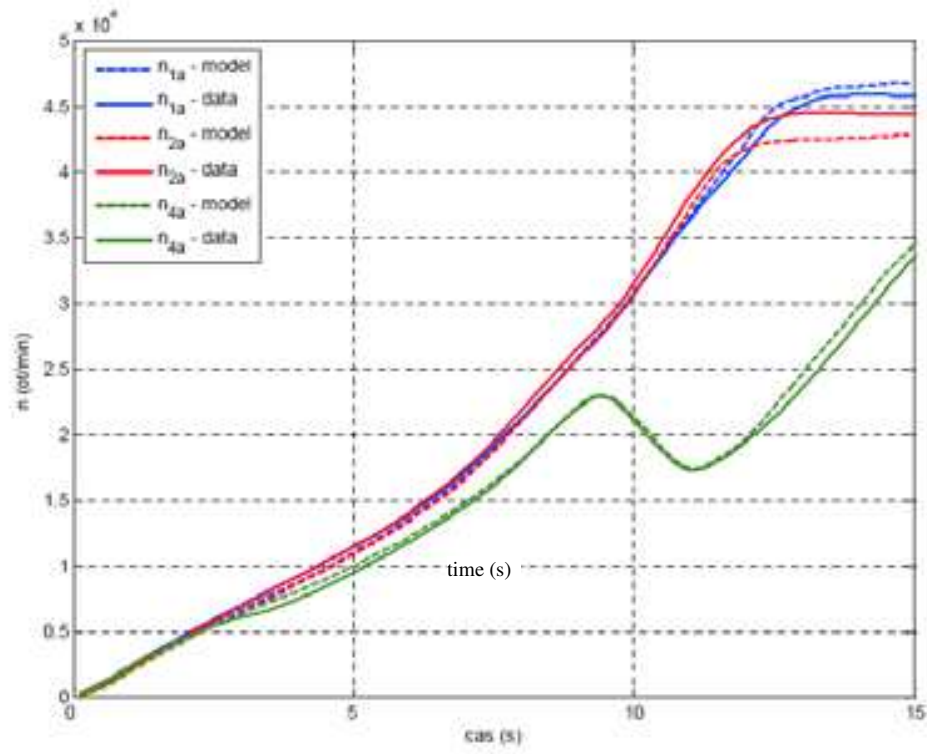

Fig. 12. The results of the start-up model for different levels of input signal 
Figure 13 shows simulation of a stable operation of the engine with individual models in the form of TSK fuzzy inference systems (FIS).

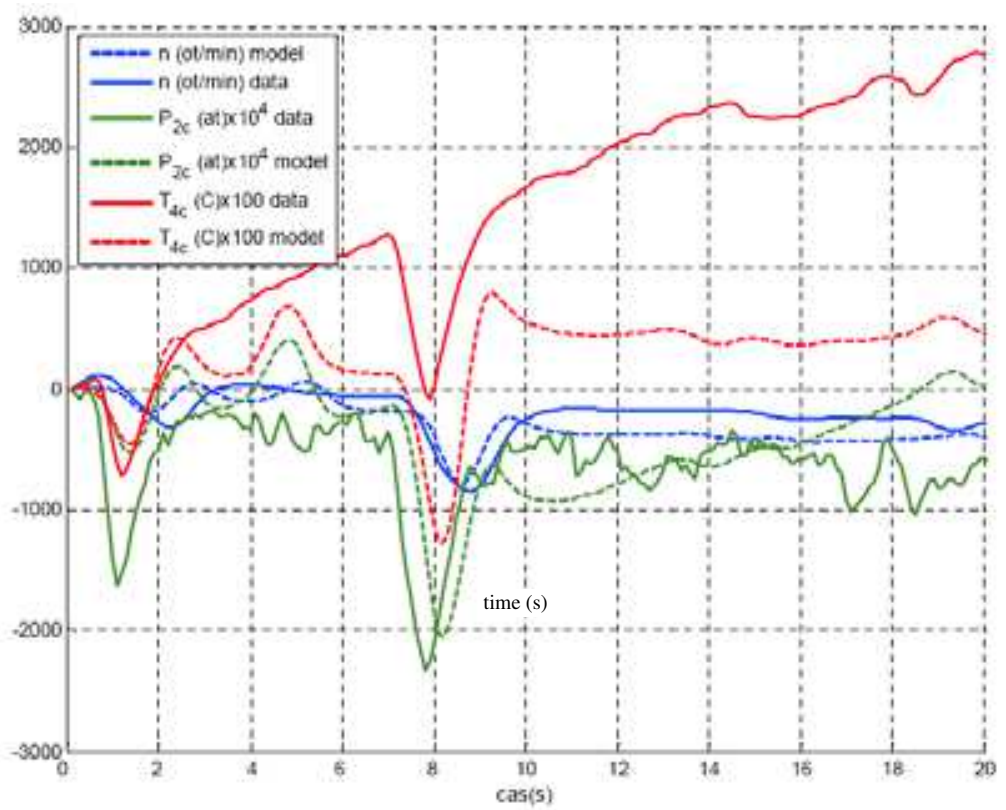

Fig. 13. One run of the engine in simulation of differences of all variables in the stable regime.

The problematic area in this case is temperature $\mathrm{T}_{4 \mathrm{c}}$, because by use of the FIS TSK model we aren't able to simulate overheating of the engine as time of operation isn't the input parameter. Simulation of the whole operation of MPM20 engine is shown in the figure 13. The errors of simulation of 15 different measured runs of the engine in its whole operation are summarized in the table 1 . The table shows means of mean absolute (MAE) and the maximum absolute error (MAAE).

\begin{tabular}{|l|c|c|c|c|}
\hline Parameter & $\mathrm{MAE}_{\mathrm{i}=1 \ldots 15}$ & $\mathrm{MAAE}_{\mathrm{i}=1 \ldots 15}$ & $\mathrm{MAPE}_{\mathrm{i}=1 \ldots 15}$ & MAAPE $_{\mathrm{i}=1 \ldots 15}$ \\
\hline $\mathrm{N}(\mathrm{rpm})$ & 67 & 275 & 0.14 & 0.61 \\
\hline $\mathrm{T}_{4 \mathrm{C}}\left({ }^{\circ} \mathrm{C}\right)$ & 13 & 56 & 1.1 & 2.7 \\
\hline $\mathrm{P}_{2 \mathrm{C}}$ (at) & 0.065 & 0.071 & 1.7 & 1.88 \\
\hline
\end{tabular}

Table 1. A summary of the MPM-20 model simulations

We can see that the maximum absolute percentage error is about $1.7 \%$ for $\mathrm{P}_{2 \mathrm{C}}$ parameter in the whole dynamic range and the maximum percentage absolute error is by $2.7 \%$ which gives way more accurate predictions than linear dynamic models. One exemplar run of the model is shown in the figure 14. 


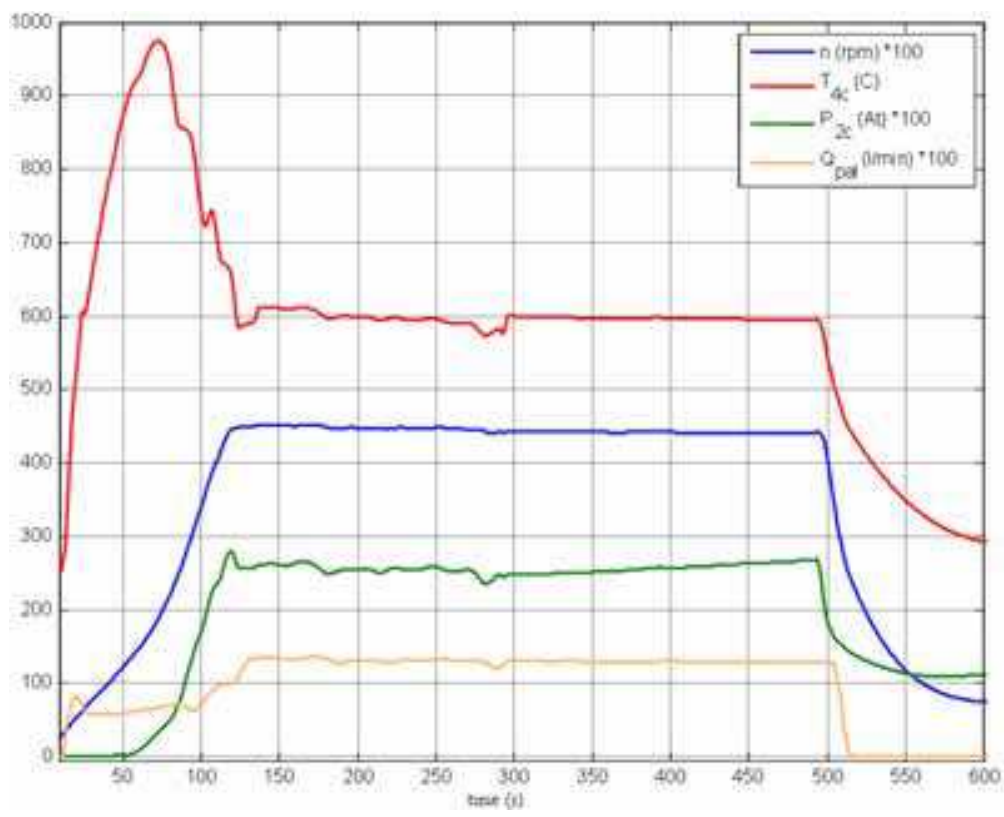

Fig. 14. One run of the engine simulated by the situational model

\section{Situational control algorithms for turbojet engines}

\subsection{Situational control algorithms of large scale systems}

Methods of artificial intelligence may offer new quality into control systems. Situational control was designed for the control of complex systems, where the traditional cybernetic models weren't sufficient (Pospelov, 1986). The model proposed in (Pospelov, 1986) wasn't sufficient to control systems characterized by features like unique dynamics, incompleteness and indeterminacy of description, ambiguity and presence of a free will.

More general approach to situational control is the following structural scheme of formatter control of complexes shown in the figure 15. Formatter control of a complex means not only the control of its parameters, but also the control of the form of the complex system.

The central element of this system is the control component, which is represented by a structure of a control component (fig 16) using methods of situational control. This means that it is a system, which makes situational classification and chooses the appropriate control strategy upon the basis of incoming signals from analyzers ANX, ANY, ANR and ANZ. The following figure shows the functional scheme of situational control of a complex system.

The control process is composed of two phases, the decision and the control phase, where every of them is divided into classification and the action phase. Processed situation is analyzed in the selection part of the decision phase (classification). According to analysis of results, the actual situation is then assigned to one of the prepared situations. Every standard situation has a certain file of control algorithms which are stored in memory or an algorithm has a file of situations that can be handled by it. During the action period of the decision-making phase, the most suitable file of algorithms is being activated to process the given situation. 


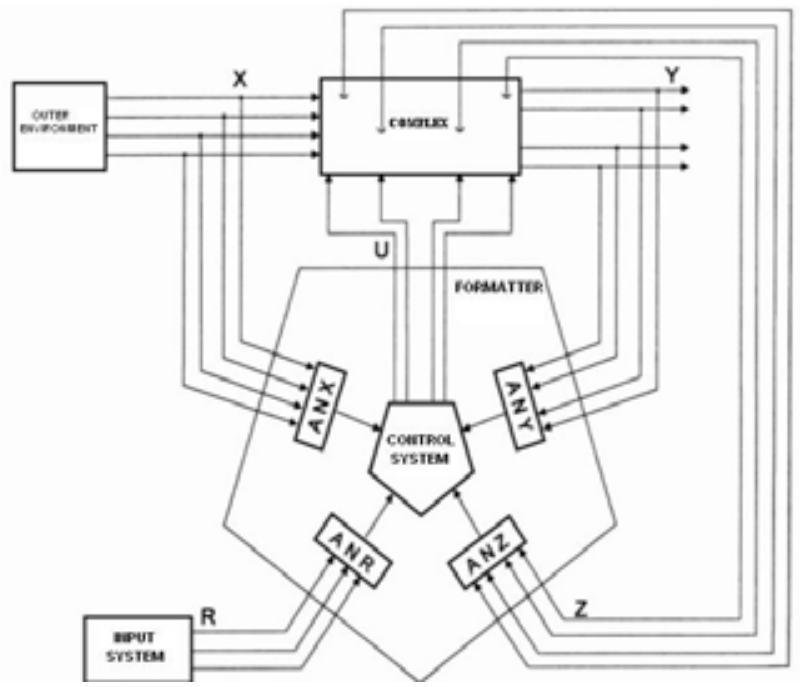

Fig. 15. Formatter control of a complex system (Beneš, 1974)

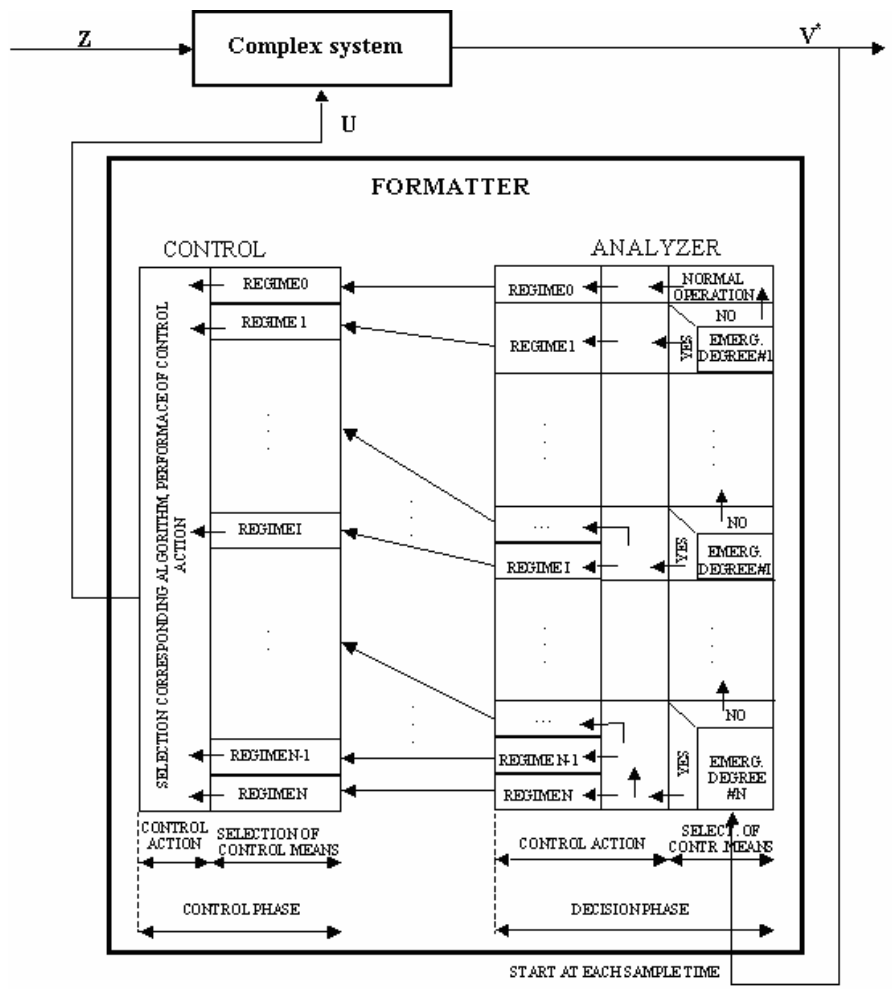

Fig. 16. Functional scheme of situational control system (Madarász, 1994) 
During the selection interval of the control phase, these algorithms adapt themselves for solution of the given situation (parameterization and other adaptation connected with activation). Realization of control activity occurs in the action period of the control phase, this control activity is passed to action elements that manipulate with the system.

For the design of a system respecting the requirements of control in anytime, the following algorithm is proposed (Madarász, 1994):

a. description of the structure and function of the controlled complex system,

b. global goal designation,

c. classification of erroneous operational states and their causes,

d. classification and description regimes functions of the control, that are assigned to individual erroneous states,

e. algorithmization of individual regimes of control,

f. implementation.

By algorithmization and design of regimes of control and also by the design of a classification mechanism, it is today necessary to consider use of robust intelligent methods for these tasks. In the past methods of multi-criteria decision making, expert systems, or catastrophe and chaos theory have been used for situational classification. A suitable approach lies today in the use of adaptive learning systems that will be covered further.

\subsection{Situational control system design for a turbojet engine}

Methods of artificial intelligence may offer new quality into control systems. However they can bring such benefits only after a careful model based analysis of a system where they should be applied with regards to simplicity and error free operation of such control system. Because on the lowest level of control we deal mostly with data and raw numbers, the approaches of sub-symbolic AI are appropriate to be used in design of intelligent FADEC control systems. However, on higher level of integration some symbolic concepts could also be used. From the area of symbolic AI three basic approaches can be successfully used:

- neural networks,

- fuzzy inference systems,

- $\quad$ genetic algorithms.

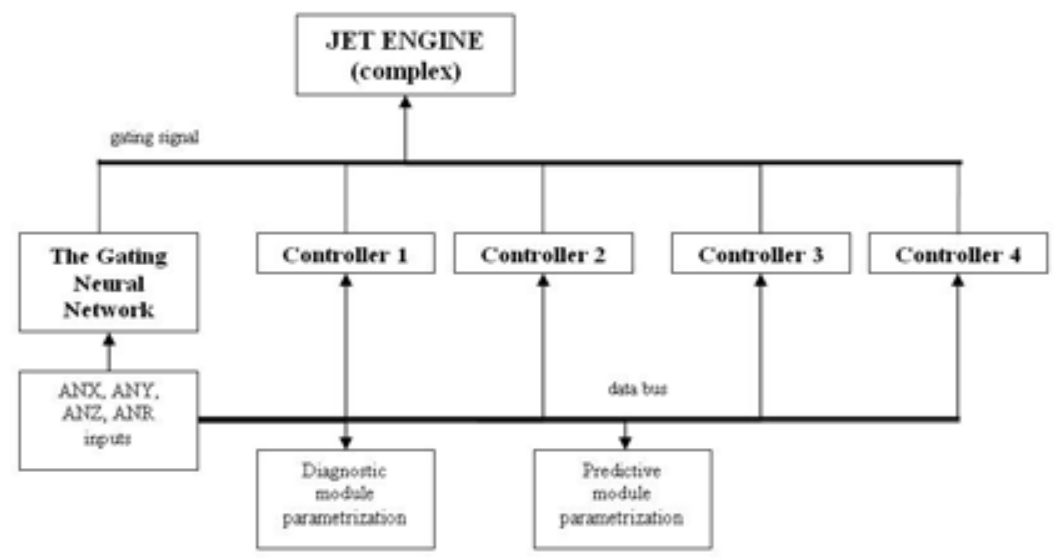

Fig. 17. General situational control system scheme to be used in turbojet engines 
All three approaches offer a vast number of methods and their combinations in hybrid architectures. Feed-forward topologies can be successfully employed mainly in modeling of non linearity of a jet engine and as decision elements in control circuits, for example as a gating neural network in general jet engine situational control formatter scheme designed by authors as shown in the figure 17 .

The whole concept of the situational control system is decomposition of operational states into time spaced situational frames (classes) and every situational frame has at least one corresponding control algorithm (or controller) assigned to handle it. Special attention is put on handling of critical states. The exemplar system in the figure 17 handles only four basic situational frames.

\subsection{Situational control system of the MPM-20 engine}

In development and design of FADEC (Full Authority Digital Engine Control) compliant control system, situational control methodology approach has been used. It is similar in to the one described in previous chapter, what means we use a gating neural network as a classifier of situational frames and system of controllers to handle those situational frames. We use concepts of traditional situational control and formatter control of complex systems. The resulting physical architecture including analyzers of input $(X)$, state $(\mathrm{Z})$, output $(\mathrm{Y})$ and desired (R) parameters is shown in the figure 18

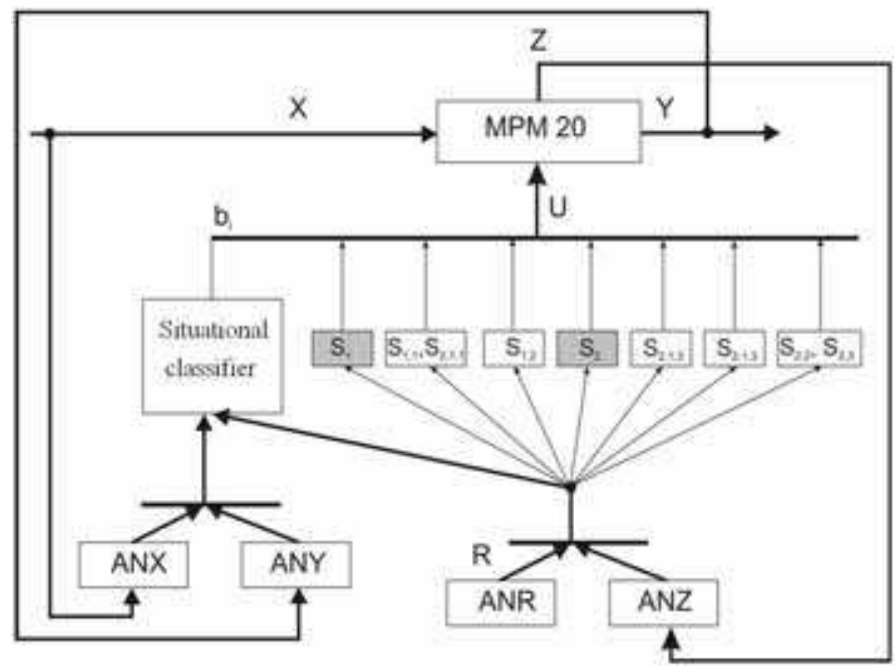

Fig. 18. Implementation of situational control system with decomposition into situational frames

Blocks designated as $S_{i, j, k}$ represent controllers for different situational frames, which result from the situational decomposition of operation of the engine in three levels:

- $\quad$ start-up of the engine - situational frame $S_{1}$

- $\quad$ steady operational state - situational frame $S_{2}$

- $\quad$ shut down - situational frame $S_{3}$

The whole decomposition is done with use of expert knowledge in the area and data clustering algorithms. Full situational decomposition of states is shown in the figure 18. 


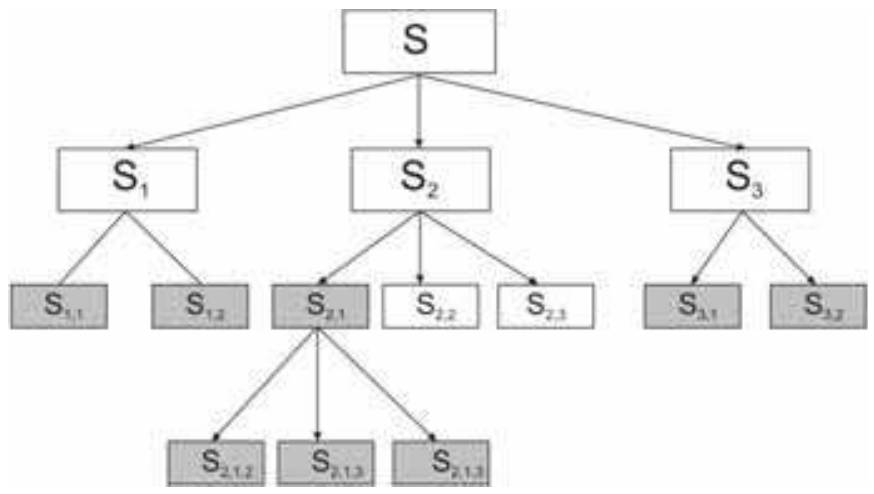

Fig. 19. Situational decomposition into situational frames

The blocks in the figure 18 have the following meaning:

$\underline{S}_{1}$ - startup of the engine:

$\mathrm{S}_{1,1}$-temperature problem, $\mathrm{S}_{1,2}$-pressure $\mathrm{P}_{2 \text { c problem }}$

$\underline{S}_{2}$ - steady state of operation:

$\underline{S}_{2,1}$ - atypical state:

$\mathrm{S}_{2,1,1}$ : low compression, $\mathrm{S}_{2,1,2}$ - low fuel flow, $\mathrm{S}_{2,1,3}$ - unstable speed,

$\mathrm{S}_{2,2}$ - acceleration, $\mathrm{S}_{2,3}$ - deceleration

$\underline{S}_{3}-$ shutdown

$S_{3,1}-$ stall of the engine

$\mathrm{S}_{3,2}$ - error by run-down

The grey blocks in the figure 19 represent atypical situational frames and every frame has defined control strategy while the switching element is done by feed-forward neural network with time delays on input, trained by scaled conjugate gradient algorithm. The next chapter will cover design of one controller that handles situational frames $S_{1}$ and $S_{1,1}$.

\subsection{Start-up controller design for the MPM-20 engine}

In design of control algorithms as elements of an integrated control circuit fuzzy inference systems can be successfully used. Such system has been used to design a startup controller for MPM 20 - the experimental small turbojet engine. This controller is acting only by startup of the engine and its aim is to decrease the temperature overshoot by startup that decreases life cycle of the engine and in certain cases can lead to turbine engine damage. The present startup techniques are mainly time based, what means that the fuel flow input is increased in a time based function rather than parameter based. The control algorithm can be seen as controller $S_{1}$ in the figure 18 and is bound with digitally controlled servo vent for fuel supply control.

The basic idea is to decompose the startup process of the engine into model microsituational frames, where one rule of the inference system would correspond to one microsituational frame in the start-up macro-situational frame.

Each rule in the form of $<\mathrm{IF}>\ldots<\mathrm{THEN}>\ldots$ postulate has a corresponding output value of fuel supply assigned. In this way we can handle not only the classical situations at startup, but also emergency situations like flameout of the engine or fire in the engine at startup. Three inputs and one output were chosen for the rules so the rule looks like this: 
IF T4c IS $L\{T 4 c\}$ AND $d T 4 c$ IS $L\{d T 4 c\}$ and $n$ IS $L\{n\}$ THEN Qpal IS L\{Qpal $\}$

where

$\mathrm{T}_{4 \mathrm{c}}$ - temperature of gases behind the turbine

$\mathrm{dT}_{4 \mathrm{c}}$ - derivation of temperature of gases behind the turbine

$\mathrm{n}$ - speed of the engine

$\mathrm{Q}_{\text {pal }}$ - fuel flow supply to the engine

$\mathrm{L}$ - function that assigns fuzzy membership function in corresponding universe of the afore mentioned parameters

In this way the fuzzy controller handles 60 micro-situations with a small excerpt shown in the following table.

\begin{tabular}{|c|c|c|c|c|c|c|c|c|c|c|c|c|c|}
\hline 29 & if & $\mathbf{n}$ & is PS & and & $\mathbf{T}_{4}$ & is $\mathrm{PB}$ & and & $\mathrm{dT}_{4}$ & is PS & THEN & $\mathbf{Q}_{\mathrm{pal}}$ & is PS & \\
\hline 30 & if & II & is PS & and & $\mathrm{T}_{4}$ & is $\mathrm{PB}$ & and & $\mathrm{dT}_{4}$ & is PM & THEN & $Q_{\text {pal }}$ & is PS & Critical $\mathrm{T}_{4}$ \\
\hline 31 & if & $\mathbf{n}$ & is $\mathrm{PM}$ & and & $\mathbf{T}_{4}$ & is PS & and & $\mathrm{dT}_{4}$ & is NM & THEN & $\mathbf{Q}_{\mathrm{pal}}$ & is $\mathrm{Z}$ & Flameout \\
\hline 32 & if & $\mathbf{n}$ & is $\mathrm{PM}$ & and & $\mathbf{T}_{4}$ & is PS & and & $\mathrm{dT}_{4}$ & is NS & THEN & $\mathbf{Q}_{\mathrm{pal}}$ & is $\mathrm{Z}$ & Flameout \\
\hline 33 & if & $\mathbf{n}$ & is $\mathrm{PM}$ & and & $\mathbf{T}_{4}$ & is PS & and & $\mathrm{dT}_{4}$ & is $\mathrm{Z}$ & THEN & $\mathbf{Q}_{\mathrm{pal}}$ & is $\mathrm{Z}$ & Flameout \\
\hline 34 & if & $\mathbf{n}$ & is $\mathrm{PM}$ & and & $\mathbf{T}_{4}$ & is PS & and & $\mathrm{dT}_{4}$ & is PS & THEN & $\mathbf{Q}_{\mathrm{pal}}$ & is $\mathrm{PB}$ & \\
\hline 35 & if & $\mathbf{n}$ & is $\mathrm{PM}$ & and & $\mathbf{T}_{4}$ & is PS & and & $\mathrm{dT}_{4}$ & is $\mathrm{PM}$ & THEN & $\mathbf{Q}_{\mathrm{pal}}$ & is PS & \\
\hline 36 & if & $\mathbf{n}$ & is $\mathrm{PM}$ & and & $\mathbf{T}_{4}$ & is $\mathrm{PM}$ & and & $\mathrm{dT}_{4}$ & is $\mathrm{NM}$ & THEN & $\mathbf{Q}_{\mathrm{pal}}$ & is $\mathrm{PB}$ & \\
\hline 37 & if & $\mathbf{n}$ & is $\mathrm{PM}$ & and & $\mathbf{T}_{4}$ & is $\mathrm{PM}$ & and & $\mathrm{dT}_{4}$ & is NS & THEN & $\mathbf{Q}_{\mathrm{pal}}$ & is $\mathrm{PB}$ & \\
\hline 38 & if & $\mathrm{n}$ & is PM & and & $\mathrm{T}_{4}$ & is $\mathrm{PM}$ & and & $\mathrm{dT}_{4}$ & is $Z$ & THEN & $\mathrm{Q}_{\mathrm{pal}}$ & is $\mathrm{PB}$ & Final rule \\
\hline 39 & if & $\mathbf{n}$ & is $\mathrm{PM}$ & and & $\mathbf{T}_{4}$ & is $\mathrm{PM}$ & and & $\mathrm{dT}_{4}$ & is PS & THEN & $\mathbf{Q}_{\mathrm{pal}}$ & is $\mathrm{PM}$ & \\
\hline 40 & if & $\mathbf{n}$ & is $\mathrm{PM}$ & and & $\mathbf{T}_{4}$ & is $\mathrm{PM}$ & and & $\mathrm{dT}_{4}$ & is $\mathrm{PM}$ & THEN & $\mathbf{Q}_{\mathrm{pal}}$ & is PS & \\
\hline 41 & if & $\mathbf{n}$ & is $\mathrm{PM}$ & and & $\mathbf{T}_{4}$ & is PB & and & $\mathrm{dT}_{4}$ & is $\mathrm{NM}$ & THEN & $\mathbf{Q}_{\mathrm{pal}}$ & is $\mathrm{PM}$ & \\
\hline 42 & if & $\mathbf{n}$ & is $\mathrm{PM}$ & and & $\mathbf{T}_{4}$ & is $\mathrm{PB}$ & and & $\mathrm{dT}_{4}$ & is NS & THEN & $\mathbf{Q}_{\mathrm{pal}}$ & is $\mathrm{PM}$ & \\
\hline 43 & if & n & is PM & and & $\mathrm{T}_{4}$ & is $\mathrm{PB}$ & and & $\mathrm{dT}_{4}$ & is $Z$ & THEN & $Q_{\text {pal }}$ & is PS & Critical $\mathrm{T}_{4}$ \\
\hline 44 & if & $\mathbf{n}$ & is $\mathrm{PM}$ & and & $\mathbf{T}_{4}$ & is $\mathrm{PB}$ & and & $\mathrm{dT}_{4}$ & is PS & THEN & $\mathbf{Q}_{\mathrm{pal}}$ & is $Z$ & \\
\hline 45 & if & $\mathbf{n}$ & is $\mathrm{PM}$ & and & $\mathbf{T}_{4}$ & is $\mathrm{PB}$ & and & $\mathrm{dT}_{4}$ & is $\mathrm{PM}$ & THEN & $\mathbf{Q}_{\mathrm{pal}}$ & is $\mathrm{Z}$ & Fire \\
\hline 46 & if & $\mathbf{n}$ & is $\mathrm{PB}$ & and & $\mathbf{T}_{4}$ & is PS & and & $\mathrm{dT}_{4}$ & is $\mathrm{NM}$ & THEN & $\mathbf{Q}_{\mathrm{pal}}$ & is $Z$ & Flameout \\
\hline 47 & if & $\mathbf{n}$ & is $\mathrm{PB}$ & and & $\mathbf{T}_{4}$ & is PS & and & $\mathrm{dT}_{4}$ & is NS & THEN & $\mathbf{Q}_{\mathrm{pal}}$ & is $\mathrm{Z}$ & Flameout \\
\hline
\end{tabular}

Table 2. Rules for the start-up controller of the MPM-20 engine

Where rules in yellow color represent critical temperature states, blue color represent stall of the engine, red color represents rule handling fire of the engine and green color represents the final rule after execution of which control is handled to another controller and engine transits from startup macro-situation into another macro situational frame. The last figure shows the control surfaces of the startup macro-situation for MPM-20 engine.

The proposed controller for the start-up of the MPM-20 will be included into the whole situational control system and is awaiting further testing in laboratory conditions. Although the controller is used only for specific situational frame, it can be further developed and used on normal sized engines of similar type. 

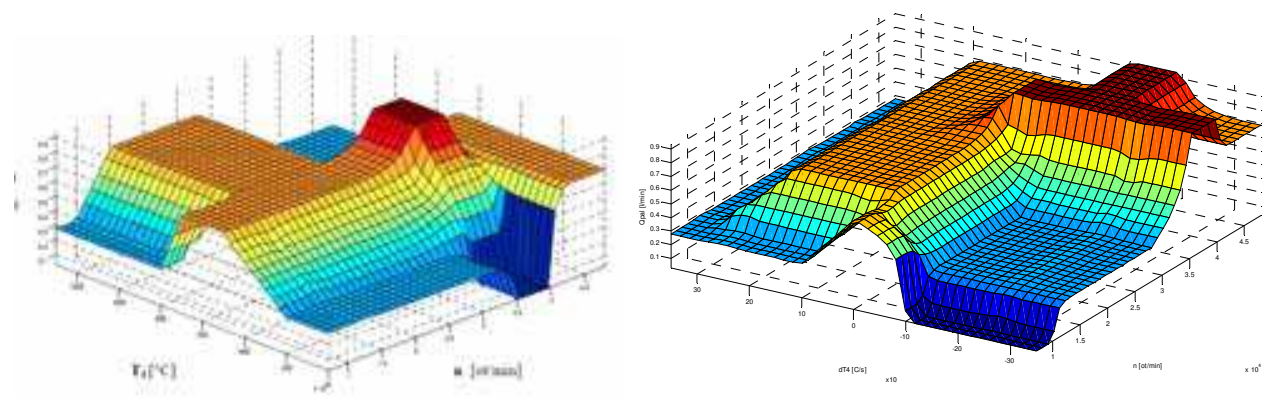

Fig. 20. Control surfaces of the startup controller

\section{Conclusion}

The article presented some basic approaches in modeling and control of turbojet engines in general and applied for the object of the MPM-20 engine. This engine gives us an ideal test bed for research of methods in the areas of non-linear dynamic systems modeling and design of advanced control algorithms. Further research will be done in the area of situational modeling that will be headed towards broadening of input parameters of the situational model of the engine and further refinement situational classes. In this area we will be aimed at use of automatic algorithms to find boundaries between situational frames within multivariate space of parameters contrary to their setting by an expert. This also applies for situational control algorithm with the main aim lying in research of adaptive situational classifier systems that will be able to create classes and automatically assign controllers for them. All research in the areas of situational modeling, situational control should bring new quality of control and modeling in the area of turbojet engines and we expect this knowledge to be also expanded to other areas of technical systems.

\section{Acknowledgement}

The work described in this chapter has been supported by VEGA num. 1/0394/08 "Algorithms of situational control and modelling of complex systems "and KEGA no. 001010TUKE-4/2010 - Use of intelligent methods in modelling and control of aircraft engines in education.

\section{References}

Andoga, R., Madarász, L., Főző, L. (2006). Situational modeling and control of a small turbojet engine MPM 20, IEEE International Conference on Computational Cybernetics, 20.22. August, 2006, ISBN. 1-4244-0071-6, pp. 81-85., Tallinn, Estonia

Beneš, J. (1974), Teorie systémů (ř́zení komplexü)(Theory of systems), 200 pp. Academia, nakladatelství ČSAV, 1974, Czech. Rep.

Főzó, L.(2008). Use of mathematical model of steady and nonsteady operation of MPM20 turbojet engine by design of anytime control algorithms (in Slovak), Dissertation thesis, Dept. of Cybernetics and AI, Faculty of Electrical Engineerin and Informatics, Technical University of Košice, 144 p., September 2008., Slovakia 
Harris, Ch., Hong, X., Gan, Q. (2006) Adaptive Modelling, Estimation and Fusion from Data, Springer, ISBN 3-540-42686-8, pp. 323, 2006.

J.-S. Roger Jang. (1993). ANFIS: Adaptive-Network-Based Fuzzy Inference Systems," IEEE Transactions on Systems, Man, and Cybernetics, Vol. 23, No. 03, pp 665-685

Jonathan S., L., Turso, J., A., Shah, N., Sowers., T., S., Owen, K., A. (2005) A Demonstration of a Retrofit Architecture for Intelligent Control and Diagnostics of a Turbofan Engine, NASA/TM -2005-214019, USA

Lazar, T. et al. (2000), Tendencie vývoja a modelovania avionických systémov, Ministerstvo Obrany SR, pp.160, ISBN 80-8842-26-3., Slovakia

Linke-Diesenger, A. (2008). Systems of commercial turbofan engines: an introduction to systems functions, Springer, ISBN 978-3-540-73618-9

Madarász, L., Andoga R., Főző, L., Lazar. T. (2009). Situational control, modeling and diagnostics of large scale systems, In: Towards Intelligent Engineering and Information Technology, Rudas I.J., Fodor, J., Kacprzyk, J. (Ed.), p. 153-164., ISBN 978-3-64203737-5, Springer-Verlag, Berlin.

Madarász, L. (2004).: Intelligent technologies and their applications in large scale systems. University Press, elfa s.r.o. Košice, 368 pp., ISBN - 89062 - 41 - 5

Madarász, L., Holečko, P. (1994), Methodology of Situational Control Creation and its Applications. 1st IFAC Workshop, New Trends in Design of Control Systems, pp. 155 - 162. Smolenice, Slovakia

Moller, M. F. (1993), A scaled conjugate gradient algorithm for fast supervised learning, Neural Networks, vol. 6, pp. 525-533, 1993.

Pospelov, D.A (1986), Situacionnoje upravlenije. Teoria i praks. Nauka, 284 pp., Moskva

Považan J (1999).: Konštrukcia matematických modelov leteckých turbokompresorových motorov (Construction of mathematic models of aircraft engines), VLA M.R.Š. v Košiciach, ISBN 80-7166-030-2., Slovakia

Ružek, J., Kmoch, P.(1979), Teorie leteckých motoru I., 373 pp, 1979, Czech Rep.

Sanjay, G.(2005). NASA Glenn Research in Controls and Diagnostics for Intelligent Propulsion Systems, NASA/TM 2005-214036, USA

Wiseman, M. (2005). Intelligent Engine Systems, NASA CR/-2005-213964, USA 


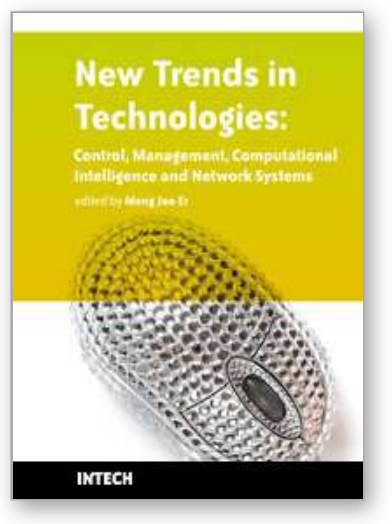

\section{New Trends in Technologies: Control, Management, Computational Intelligence and Network Systems}

Edited by Meng Joo Er

ISBN 978-953-307-213-5

Hard cover, 438 pages

Publisher Sciyo

Published online 02, November, 2010

Published in print edition November, 2010

The grandest accomplishments of engineering took place in the twentieth century. The widespread development and distribution of electricity and clean water, automobiles and airplanes, radio and television, spacecraft and lasers, antibiotics and medical imaging, computers and the Internet are just some of the highlights from a century in which engineering revolutionized and improved virtually every aspect of human life. In this book, the authors provide a glimpse of the new trends of technologies pertaining to control, management, computational intelligence and network systems.

\section{How to reference}

In order to correctly reference this scholarly work, feel free to copy and paste the following:

Ladislav Madarász, Rudolf Andoga and Ladislav Fozo (2010). Intelligent Technologies in Modeling and Control of Turbojet Engines, New Trends in Technologies: Control, Management, Computational Intelligence and Network Systems, Meng Joo Er (Ed.), ISBN: 978-953-307-213-5, InTech, Available from: http://www.intechopen.com/books/new-trends-in-technologies--control--management--computationalintelligence-and-network-systems/intelligent-technologies-in-modeling-and-control-of-turbojet-engines

\section{INTECH}

open science | open minds

\section{InTech Europe}

University Campus STeP Ri

Slavka Krautzeka 83/A

51000 Rijeka, Croatia

Phone: +385 (51) 770447

Fax: +385 (51) 686166

www.intechopen.com

\section{InTech China}

Unit 405, Office Block, Hotel Equatorial Shanghai

No.65, Yan An Road (West), Shanghai, 200040, China

中国上海市延安西路65号上海国际贵都大饭店办公楼 405 单元

Phone: +86-21-62489820

Fax: $+86-21-62489821$ 
(C) 2010 The Author(s). Licensee IntechOpen. This chapter is distributed under the terms of the Creative Commons Attribution-NonCommercialShareAlike-3.0 License, which permits use, distribution and reproduction for non-commercial purposes, provided the original is properly cited and derivative works building on this content are distributed under the same license. 